\title{
Elevated Metabolic Enzymes and its Association with Insecticide Detoxification in Culex quinquefasciatus Say
}

\section{Anju Viswan $\mathrm{K}^{*}$ and E Pushpalatha}

Biopesticides and Toxicology Laboratory, Department of Zoology, University of Calicut, Kerala, India

*Corresponding Author: Anju Viswan K, Biopesticides and Toxicology Laboratory, Department of Zoology, University of Calicut, Kerala, India.
Received: February 22, 2021

Published: March 22, 2021

(C) All rights are reserved by Anju Viswan K and E Pushpalatha.

\section{Abstract}

Background and Objectives: The detoxification mechanism of an insect describes the decreased susceptibility to an insecticide that was previously effective in controlling that insect. There is a chance for detoxification against insecticides in mosquitoes by the over usage of chemical insecticides. The identification of enhanced levels or modified activities of enzymes like esterases, oxidases, or glutathione-s-transferases (GST) can be used to improve vector control programs by the resistance management option. The current study envisage to assess and analyze detoxification enzyme levels of $C x$. quinquefasciatus of Kozhikode, Cochin, Malappuram, Thrissur, and Palakkad town areas of Kerala, India.

Methods: The samples were collected from regularly insecticide spraying area and scarcely spraying area of the five locations in the year 2014, 15 and 16 . The assays were done according to the protocol provided in techniques to detect insecticide resistance mechanism; Field and laboratory Manual [1].

Results: There is a significant difference in carboxylesterase, GST, MFO activities of field populations of Cx. quinquefasciatus with that of laboratory populations. The detoxification enzyme levels of $C x$. quinquefasciatus were high in the areas where insecticides sprayed regularly when compared to the areas where insecticides are sprayed scarcely.

Interpretation and Conclusion: The level of enzymes increased from year to year and it reinforces the need for constant surveillance of mosquito populations susceptibility against the insecticides used in control and it points to the need of employing new phytochemicals or other insecticides in the field as an alternative to synthetic chemical pesticides which would be easily degradable and have less harmful effect on other organisms.

Keywords: Culex quinquefasciatus; Insecticide Resistance; Detoxification Enzymes

\section{Introduction}

Lymphatic filariasis (LF) is a major public health problem in India. India contributes to $41 \%$ of the global disease burden [2]. Kerala ranks second in endemicity preceded only by Bihar (over $17 \%$ ) [3]. Out of the 14 districts in Kerala, 11 coastal districts (Thiruvananthapuram, Kollam, Kottayam, Alappuzha, Cochin, Thrissur, Palakkad, Malappuram, Kozhikode, Kannur and Kasar- god) are endemic for this disease [4]. But due to the effective MDA program and vector control activities the cases were reduced and now Kerala is reaching the stage of elimination of filariasis.

Vector control plays an important role in the eradication or control of the disease. The National Filaria Control Programme (NFCP), launched in 1955, insisted on providing due importance to vector control by anti-larval measures in urban areas, and indoor residual 
spraying in rural areas. However, the continuous application of synthetic insecticides renders development of resistance in target insects. The development of resistance in vector species, and emergence of new resistant genotypes among the vector population has been a major setback in the global efforts to control vector-borne diseases [5].

The metabolic based insecticide resistance mechanisms mainly include non-specific esterase, Glutathione-S-transferase (GSTs) and P450 mediated monooxygenase (MFOs) and they were known to be involved in the detoxification of organophosphate, carbamate and pyrethroid insecticides. So, these enzymes are used as reliable markers to assess the impact of toxic compounds on insects [6].

Identification of resistance mechanism helps to determine the cross resistance spectrum and facilitate the choice of alternate insecticides and helps in the mapping of areas with insecticide resistance population [7]. Microplate assay similar to other resistance detection assay should be simple and detect detoxification enzyme levels in single mosquitoes. The results of the tests are more accurate and obtained within minutes.

The scope of the current study aims to assess and analyze the resistance status of field populations of $C x$. quinquefasciatus against the organophosphorus insecticide temephos of the Calicut, Cochin, Malappuram, Thrissur and Palakkad town areas of Kerala. Temephos is an organophosphate (OP) insecticide, recommended as a larvicide by the World Health Organization (WHO) to control mosquitoes, midges, blackfly, and other infesting insects [8]. Temephos is widely using in the selected areas for the control of mosquito larvae. The present study analyses the detoxification enzyme (carboxylesterase, glutathione -S - transferase, mixed function oxidase) levels in the selected field and laboratory population of $C x$. quinquefasciatus in the three consecutive years 2014, 15 and 16 by biochemical assays.

\section{Materials and Methods}

Areas of sample collection

The larvae of $C x$. quinquefasciatus were collected from five different areas of Kerala state, India viz, Cochin Municipal Corporation, Kozhikode Corporation, Palakkad Municipality, Ponnani Municipality (Malappuram) and Thrissur Municipal Corporation. From each of the area, depending upon the mosquito control regimes in existence, collections were made from two different lo- cations i.e. i) the regularly insecticide spraying locations (T) and ii) scarcely spraying locations (U). In all these areas temephos was used as a larvicide for the control of Culex mosquitoes by the Municipality/Corporation. Recently, they have started using Bti as larvicide in all the five areas and alternatively, Temephos and Bti were predominantly used by Ponnani Municipality (as per the reports of Municipality Health Dept.). The District vector control unit also sprays temephos as larvicide in all these areas as a control measure for Culex mosquitoes. Susceptible Laboratory Populations were collected from CRME (Centre for Research in Medical Entomology) ICMR, Madurai. The areas of collection are denoted as LAB - Laboratory, EKM - Cochin Municipal Corporation, CLT - Kozhikode Corporation, PKD - Palakkad Municipality, MPM - Ponnani Municipality and TCR - Thrissur Corporation.

\section{Biochemical assays}

Biochemical assays were used to quantify levels of monooxygenases and non-specific esterases, in $4^{\text {th }}$ instar larvae of the F1 generation. 30 fourth instar larvae were taken from each of the samples for the assays. The assays were done according to the protocol provided in techniques to detect insecticide resistance mechanism; Field and Laboratory Manual [1], [Techniques to detect insecticide resistance mechanisms, WHO/ CDS/ CPC/MAI: / 98; 6]. Total protein was measured using the protocol of Bradford [9].

\section{Statistical analysis}

Statistical analysis (ANOVA) was performed using Statistical package SPSS 20.0 .

\section{Results}

The carboxylesterase levels indicated the degree of detoxification to insecticides. High levels of these enzymes are seen in several organophosphate resistant strains of a number of insect species as compared to susceptible strains of the same insect.

The increased enzyme activity is represented in the following tables. It is calculated using the formula: (The activity in the present year - The activity in the previous year)/The activity in the previous year X 100 .

$\alpha$ esterase activity increase (Table 1) in EKM population was $11.11 \%$ in the year 2016 as compared with the year 2014. The level of increase from the 2015 to 2016 was less as compared with level of increase in 2014 to 2016 . More than 5\% activity increase was 
obtained in PKD, TCR, CLT and EKM. But only at PKD the scarcely treating area also shows a value of increased activity more than 5.

\begin{tabular}{|l|c|c|c|}
\hline $\begin{array}{c}\text { Area of } \\
\text { sample } \\
\text { collection }\end{array}$ & $\begin{array}{c}\text { Increased } \\
\text { activity \% in } \\
\mathbf{2 0 1 5} \text { from } \\
\mathbf{2 0 1 4}\end{array}$ & $\begin{array}{c}\text { Increased } \\
\text { activity \% in } \\
\mathbf{2 0 1 6} \text { from } \\
\mathbf{2 0 1 5}\end{array}$ & $\begin{array}{c}\text { Increased } \\
\text { activity \% } \\
\text { in 2016 } \\
\text { from 2014 }\end{array}$ \\
\hline LAB & -1.105 & 1.117 & 0 \\
\hline MPM U & 3.810 & 0.459 & 4.286 \\
\hline MPM T & 3.571 & 0.000 & 3.571 \\
\hline PKD U & 3.774 & 1.818 & 5.660 \\
\hline PKD T & 5.394 & 1.575 & 7.054 \\
\hline TCR U & 3.636 & 0.877 & 4.545 \\
\hline TCR T & 4.938 & 1.961 & 6.996 \\
\hline CLT U & 2.703 & 1.754 & 4.505 \\
\hline CLT T & 5.814 & 3.297 & 9.302 \\
\hline EKM U & 4.484 & -0.429 & 4.036 \\
\hline EKM T & 8.889 & 2.041 & 11.111 \\
\hline
\end{tabular}

Table 1: Increased activity of $\alpha$ esterase level in the field and laboratory populations of $C x$. quinquefasciatus.

Increased activity of $\beta$ esterase (Table 2 ) was shown by TCR and CLT as compared with other areas. The activity increase percentage of TCR Culex population in 2015/2014, 2016/2015, 2016/2014 was $7.556,7.438$ and 15.556 respectively.

\begin{tabular}{|l|c|c|c|}
\hline $\begin{array}{c}\text { Area of } \\
\text { sample } \\
\text { collection }\end{array}$ & $\begin{array}{c}\text { Increased } \\
\text { activity \% in } \\
\mathbf{2 0 1 5} \text { from } \\
\mathbf{2 0 1 4}\end{array}$ & $\begin{array}{c}\text { Increased } \\
\text { activity \% } \\
\text { in 2016 } \\
\text { from 2015 }\end{array}$ & $\begin{array}{c}\text { Increased } \\
\text { activity \% } \\
\text { in 2016 } \\
\text { from 2014 }\end{array}$ \\
\hline LAB & 0.562 & 0.00 & 0.562 \\
\hline MPM U & 1.485 & 0.488 & 1.980 \\
\hline MPM T & 2.283 & 1.786 & 4.110 \\
\hline PKD U & 1.961 & 2.885 & 4.902 \\
\hline PKD T & 3.879 & 5.809 & 9.914 \\
\hline TCR U & 2.913 & 2.830 & 5.825 \\
\hline TCR T & 7.556 & 7.438 & 15.556 \\
\hline CLT U & 1.852 & 1.818 & 3.704 \\
\hline CLT T & 5.882 & 7.143 & 13.445 \\
\hline EKM U & 3.670 & 1.327 & 5.046 \\
\hline EKM T & 4.120 & 5.036 & 9.363 \\
\hline
\end{tabular}

Table 2: Increased activity of $\boldsymbol{\beta}$ esterase level in the field and laboratory populations of $C x$. quinquefasciatus.
The glutathione-S-transferases (GSTs) are members of a large family of multifunctional intracellular enzymes involved in the detoxification of endogenous and xenobiotic compounds via glutathione conjugation, dehydrochlorination, glutathione peroxidase activity or passive/sacrificial binding [10,11]. Elevated levels of GST activity have been found to be associated to insecticide resistance in mosquitoes have often been implicated in the resistance to organophosphates (OPs), organochlorine (OC) and pyrethroids. In the present study the GST levels were elevated in all cases and the results are as follows (Figure 3 ).

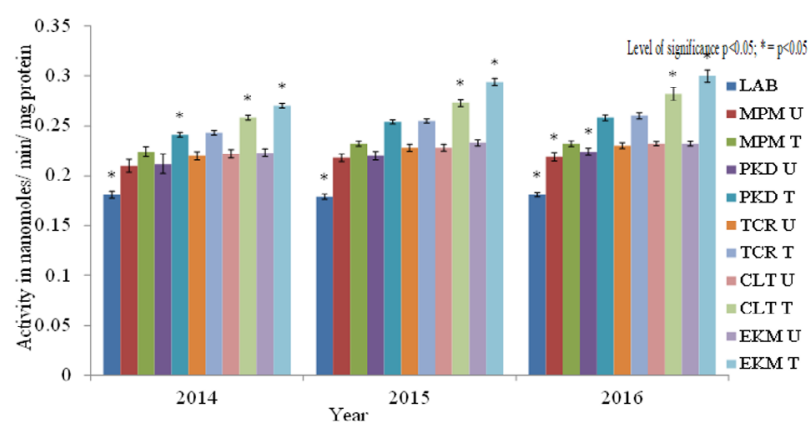

Figure 1: $\alpha$ esterase levels in the laboratory and field populations of $C x$. quinquefasciatus during 2014, 15 and 16.

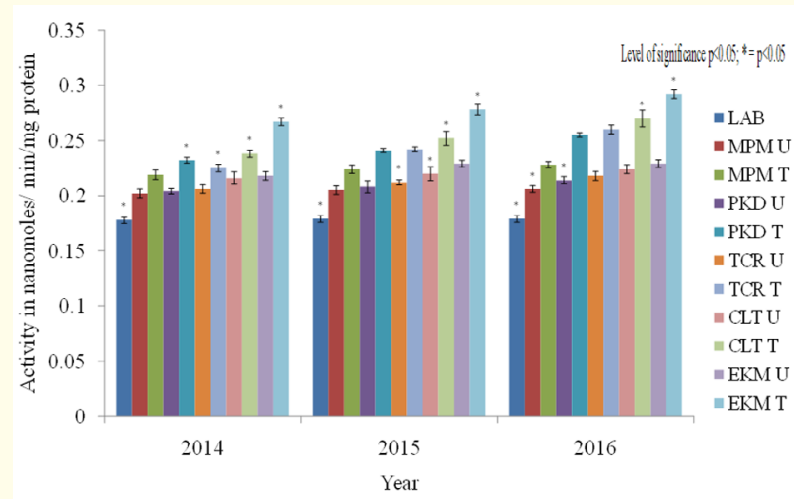

Figure 2: $\beta$ esterase levels in the laboratory and field populations of Cx. quinquefasciatus during 2014, 15 and 16.

Table 3 exhibits data on the increased levels of GST enzyme activity in the field and laboratory populations from the previous 


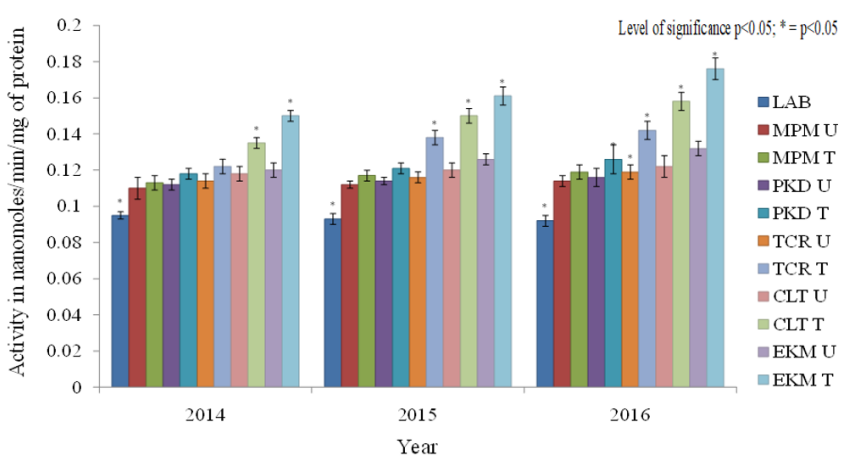

Figure 3: GST levels in the laboratory and field populations of Cx. quinquefasciatus during 2014, 15 and 16.

years, the comparison of data reveals the hike of enzyme activity. EKM, CLT and TCR population have a higher value of increase in the enzyme activity whereas the MPM population has the least value.

\begin{tabular}{|l|c|c|c|}
\hline $\begin{array}{c}\text { Area of sample } \\
\text { collected }\end{array}$ & $\begin{array}{c}\text { Increased } \\
\text { activity \% in } \\
\mathbf{2 0 1 5 \text { from }} \\
\mathbf{2 0 1 4}\end{array}$ & $\begin{array}{c}\text { Increased } \\
\text { activity \% } \\
\text { in 2016 } \\
\text { from 2015 }\end{array}$ & $\begin{array}{c}\text { Increased } \\
\text { activity \% } \\
\text { in 2016 } \\
\text { from 2014 }\end{array}$ \\
\hline LAB & -2.105 & -1.075 & -3.158 \\
\hline MPM U & 1.818 & 1.786 & 3.636 \\
\hline MPM T & 4.425 & 0.847 & 5.310 \\
\hline PKD U & 1.786 & 1.754 & 3.571 \\
\hline PKD T & 2.542 & 4.132 & 6.780 \\
\hline TCR U & 1.754 & 2.586 & 4.386 \\
\hline TCR T & 13.115 & 2.899 & 16.393 \\
\hline CLT U & 1.695 & 1.667 & 3.390 \\
\hline CLT T & 11.111 & 5.333 & 17.037 \\
\hline EKM U & 5.000 & 4.762 & 10.000 \\
\hline EKM T & 8.000 & 8.642 & 17.333 \\
\hline
\end{tabular}

Table 3: Increased activity of GST level in the field and laboratory populations of $C x$. quinquefasciatus.

P450 mediated monooxygenase (MFOs) are known to be involved the detoxification of organophosphate, pyrethroid and carbamate insecticides [12]. Among these mixed function oxidase resistance to pyrethroids was more predominant. The monooxy- genase activity in terms of optical density was represented in figure 4. Year wise enzyme activity data of insecticide regularly treating area shown an upward trend with time, through that exhibited significant $(p<0.05)$ increase in resistance. There is significant change between the laboratory and field populations.

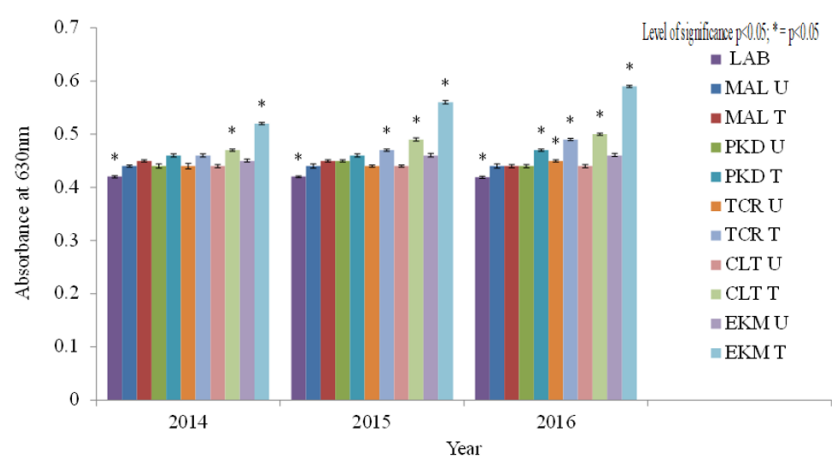

Figure 4: MFO levels in the laboratory and field populations of Cx. quinquefasciatus during 2014, 15 and 16.

The increased MFO enzyme activity levels of the field and laboratory population from the previous years were depicted in the table 4. Comparison revealed the uphill of enzyme activity during the study period. EKM, Culex populations have a higher value (13.46\%) of increase in the enzyme activity whereas the MPM, PKD populations have no change in the enzyme activity and the TCR and CLT populations have 6.52 and $6.38 \%$ increase from 2014 to 2016 .

\section{Discussion and Conclusion}

The best method of choice for understanding the mechanism of insecticide resistance among insects is the biochemical estimations. Biochemical assays are sophisticated and highly sensitive, so it analyzes the mechanisms of insecticide resistance with a fair degree of accuracy. Metabolic detoxification is the most common resistance mechanism that occurs in almost all insects. In mosquitoes it occurs due to changes in its enzyme systems that result in a more rapid detoxification of the insecticide than what is normal, preventing the insecticide from reaching the intended site of action [5].

Elevated esterase activity accounts for resistance to organophosphates, carbamates and pyrethroid insecticides [13]. The 


\begin{tabular}{|l|c|c|c|}
\hline $\begin{array}{c}\text { Area of } \\
\text { samples } \\
\text { collected }\end{array}$ & $\begin{array}{c}\text { Increased } \\
\text { activity \% } \\
\text { in 2015 from } \\
\mathbf{2 0 1 4}\end{array}$ & $\begin{array}{c}\text { Increased } \\
\text { activity \% } \\
\text { in 2016 from } \\
\mathbf{2 0 1 5}\end{array}$ & $\begin{array}{c}\text { Increased } \\
\text { activity \% } \\
\text { in 2016 } \\
\text { from 2014 }\end{array}$ \\
\hline LAB & 0.00 & 0.00 & 0.00 \\
\hline MPM U & 0.00 & 0.00 & 0.00 \\
\hline MPM T & 0.00 & -2.22 & -2.22 \\
\hline PKD U & 2.27 & -2.22 & 0.00 \\
\hline PKD T & 0.00 & 2.17 & 2.17 \\
\hline TCR U & 0.00 & 2.27 & 2.27 \\
\hline TCR T & 2.17 & 4.26 & 6.52 \\
\hline CLT U & 0.00 & 0.00 & 0.00 \\
\hline CLT T & 4.26 & 2.04 & 6.38 \\
\hline EKM U & 2.22 & 0.00 & 2.22 \\
\hline EKM T & 7.69 & 5.36 & 13.46 \\
\hline
\end{tabular}

Table 4: Increased activity of MFO levels in the field and laboratory populations of $C x$. quinquefasciatus.

increase in enzyme activity also noted and it supports the results that there is high level of change in the detoxification enzymes in the field population. $\alpha$ esterase activity increase in EKM population was 11.11 fold higher in the year 2016 as compared with the year 2014. In the year 2015 the percentage increase was 8.89 from the year 2014 but there is no a higher increase from the year 2015 to 2016 and it was 2.04. The level of increase from the 2015 to 2016 was less as compared with level of increase in 2014 to 2015. More than 5 fold increases was obtained in PKD, TCR, CLT and EKM population during these three consecutive years. But only in the case of PKD, the scarcely treating area showed an increased value of activity more than five. Increased activity of $\beta$ esterase was shown by TCR and CLT as compared with other areas. The activity increase of TCR $C x$. population in 2015/2014, 2016/2015, 2016/2014 was 7.556, 7.438 and 15.556 respectively. In CLT and PKD as compared with other localities there is hike in the activity level from 2015 to 2016.

Several studies have shown that insecticide-resistant insects have elevated levels of Glutathione-S-Transferase (GST) activity in crude homogenates, which suggests a role for GSTs in resistance [14], particularly to DDT [5]. Elevated GST activities have also been detected in some insect species resistant to organophosphates [15], other organochlorines [16] and implicated in resistance to pyrethroid insecticides [17].

In all the five field populations the GST levels were elevated and were highly significant. The rate of increase in GST activity is higher in TCR (13.115) and CLT (11.11) in the year 2015 and least increase at PKD (2.54). CLT holds the first position in the increased rate of activity from the year 2015 to 2016 and the rate of increase was 5.333. But when comparing the rate of increase from 2014 to 2016 EKM stands in the first position with the value 17.333 followed by CLT (17.037) and TCR (16.393). The result indicates that the field populations were exposed to multiple chemicals in the environment.

P450s are Phase I detoxification heme-thiolate enzymes catalyzing various reactions, but are best known for their monooxygenase activity, introducing reactive or polar groups into xenobiotics or endogenous compounds $[18,19]$. The enzymatic detoxifications due to mixed function oxidases are responsible for the development of resistance in insects. The mixed function oxidase system is responsible for the resistance towards organophosphates, DDT, pyrethroids and growth regulators [20]. The metabolic detoxification of mixed function oxidase (MFO) may cause the development of cross resistance. The elevated levels of MFO in the present study suggested that the detoxification by this enzyme could be implicated in the cross resistance with DDT, pyrethroids and organophosphates.

The activity levels of MFO was significantly higher in the field collected samples than the control group for all the tested populations $(\mathrm{p}<0.00001)$. There was no increase in the activity in the field populations of MPM and PKD CX. quinquefasciatus from 2014 to 2016. There was no increase from 2014 to 2015 and 4.255 fold increase from the year 2015 to 2016 at TCR. In the case of CLT population there was a hike of 2.174 fold from 2014 to 2015 and no change in the activity from 2015 to 2016. In the EKM population the increase from 2014 to 2015 and 2015 to 2016 were 3.774 and 5.455 respectively. From the results it indicated that the EKM population has cross resistance with pyrethroids, DDT and organophosphates.

There is significant change in the detoxification enzyme levels according to the area wise difference. The F value was17.935 and $\mathrm{p}$ value was zero and it is highly significant. The null hypothesis is rejected at $95 \%$ confidence interval. High level of significance was shown by PKD T, TCR T, CLT T, EKM U and EKM T with LAB. There is no significant difference in the enzyme levels of $U$ areas. Mosquitoes cultured in the laboratory condition shows the lowest enzyme 
activity. There is significant change in the enzyme levels in 2016 with 2014 , where p value is 0.019 which is less than 0.05 . And in other cases, 2014 to 2015 and 2015 to 2016 the p value is greater than 0.05 , hence there is no significant changes. The $p$ - value is 0.00 in the profile on the analysis of enzyme wise changes in the $C x$. quinquefasciatus hence the changes in detoxification enzyme levels are highly significant in the study.

As the field population of Cochin showed comparatively high resistance to organophosphates, it implies that, the strategy used for vector control in Cochin Municipal Corporation may have to be reconsidered. In general, the current strategy for mosquito control in all these areas of investigation is based primarily on the dependence of temephos by using it as a larvicidal agent by spraying in ditches, which are the main breeding sites of $C x$. quinquefasciatus.

Various insecticide selection pressures particularly from agriculture and domestic use of insecticides were suspected to be the cause of resistance to the insecticides. It also appears that the presence of urban pollutants in mosquito breeding sites probably has a direct or indirect impact on mosquito resistance. For this reason, proper management of waste, particularly in urban areas and effective regulation of use of pesticides appear to be critical in resistance management programs. One way is to reduce the mosquito population, especially in urban areas where most of the important larval habitats have been shown to be anthropogenic [6]. Such habitats can easily be managed through proper waste management, proper construction of drains and the change of the inhabitants' behaviour through proper education. Hence proper management and control measures are necessary for the control of vector mosquitoes.

\section{Acknowledgement}

We are thankful to UGC- BSR, Delhi, India for the financial support and UGC-SAP for proving the instrumentation facilities in Department of Zoology, University of Calicut.

\section{Bibliography}

1. World Health Organization/Department of Communicable Disease Prevention Control and Eradication. Techniques to detect insecticide resistance mechanisms. Field and laboratory manual. (Dr M. Zaim/WHOPES, Ed.). Geneva: World Health Organization (1998).

2. Agrawal V and Sashindran V. "Lymphatic Filariasis in India: Problems, Challenges and New Initiatives". Medical Journal Armed Forces India 62.4 (2006): 359-362.
3. National Vector Borne Disease Control Programme. Guidelines on Filariasis Control in India and its Elimination. New Delhi (2009).

4. Sabesan S., et al. "Mapping of lymphatic filariasis in India". Annals of Tropical Medicine and Parasitology 94.6 (2000): 591606.

5. Hemingway J and Ranson H. "Insecticide Resistance in Insect Vectors of Human Disease". Annual Review of Entomology 45.1 (2000): 371-391.

6. Kudom AA., et al. "Aqueous Neem Extract Versus Neem Powder on Culex quinquefasciatus: Implications for Control in Anthropogenic Habitats". Journal of Insect Science 11.142 (2011): 1-9.

7. World Health Organization. "Vector Resistance for Pesticides". WHO Technical Report Series, 818 (1992).

8. World Health Organization and the Special Programme for Research and Training in Tropical Diseases (TDR). Dengue: Guidelines for Diagnosis Treatment Prevention and Control (New Edition 2009). Geneva: World Health Organization (2009).

9. Bradford M M. "A rapid and sensitive method for the quantitation of microgram quantities of protein utilizing the principle of protein-dye binding". Analytical Biochemistry 72 (1976): 248-254.

10. Hayes J D and Wolf C R. "Role of glutathione transferase in drug resistance". In H. (Helmut) Sies and B. Ketterer (Eds.): Glutathione conjugation: mechanisms and biological significance (1988): 315-355. London: Academic Press.

11. Yang Y., et al. "Role of glutathione S-transferases in protection against lipid peroxidation. Overexpression of hGSTA2-2 in K562 cells protects against hydrogen peroxide-induced apoptosis and inhibits JNK and caspase 3 activation". The Journal of Biological Chemistry 276.22 (2001): 19220-19230.

12. Hemingway J. "Identification of a novel class of insect glutathione $\mathrm{S}$ transferases involved in resistance to DDT in the malaria vector Anopheles gambiae". Journal of Biochemistry 359 (2001): 295-304.

13. Rao DR. "Assessment of neem (Azadirachta indica A. Juss.) cake powder as a mosquito larvicide". In Proceedings of Symposium on Alternatives to Synthetic Insecticides in Integrated Pest 
Management Systems, Madurai, India (1987): 163-169.

14. Grant DF., et al. "Glutathione S-transferase isozymes in Aedes aegypti: Purification, characterization, and isozyme-specific regulation". Insect Biochemistry 21.4 (1991): 421-433.

15. Fournier D., et al. "Acetylcholinesterase. Two types of modifications confer resistance to insecticide". The Journal of Biological Chemistry 267.20 (1992): 14270-14274.

16. Grant D and Hammock B. "Genetic and molecular evidence for a trans-acting regulatory locus controlling glutathione S-transferase-2 expression in Aedes aegypti". MGG Molecular and General Genetics 234.2 (1992): 169-176.

17. Kostaropoulos I., et al. "Glutathione S-transferase in the defence against pyrethroids in insects". Insect Biochemistry and Molecular Biology 31.4-5 (2001): 313-319.

18. Ranson H., et al. "Genetic mapping of genes conferring permethrin resistance in the malaria vector, Anopheles gambiae". Insect Molecular Biology 13.4 (2004): 379-386.

19. Scott J G., et al. "Pyrethroid resistance in Culex pipiens mosquitoes". Pesticide Biochemistry and Physiology 120 (2015): 68-76.

20. Brogdon W G and McAllister J C. "Insecticide resistance and vector control”. Emerging Infectious Diseases 4.4 (1998): 605613.

\section{Assets from publication with us}

- Prompt Acknowledgement after receiving the article

- Thorough Double blinded peer review

- Rapid Publication

- Issue of Publication Certificate

- High visibility of your Published work

Website: www.actascientific.com/

Submit Article: www.actascientific.com/submission.php

Email us: editor@actascientific.com

Contact us: +919182824667 